\title{
THE USE OF MULTISTAGE EXERCISE TESTING WITH WHEEL- CHAIR ERGOMETRY AND ARM CRANKING IN SUBJECTS WITH SPINAL CORD LESIONS
}

\author{
J. R. Wicks, M.B., B.S., F.R.A.C.P., K. LymburneR, Exercise Technician, \\ S. M. DinsDale, M.D., Ph.D., F.R.C.P.(C), F.A.C.P. and N. L. Jones, M.D., F.R.C.P., \\ F.R.C.P.(C) \\ Cardio-Respiratory Unit, McMaster University Medical Centre, I200 Main Street West, \\ Hamilton, Ontario, Canada
}

Abstract. The primary aim of this investigation was to compare maximum wheelchair performance with arm cranking using a multistage progressive work load protocol. In five subjects with a wide range of neurological disability and two normal males the differences observed in maximum oxygen uptake, heart rate and ventilation during two forms of upper limbs exercise, were not significant.

Key words: Wheelchair exercise; arm cranking; performance.

\section{Introduction}

IN assessing the physiological response to exercise in subjects who have only upper limb function as a result of spinal cord injury, two types of ergometry are commonly used. Of these, arm cranking is an unskilled task and though it facilitates the measurement of maximum oxygen uptake, it does not provide assessment of the change in the mechanical efficiency of wheelchair propulsion during rehabilitation. To enhance the specificity of testing, different wheelchair ergometers have been used to measure cardio-respiratory adaptation and the mechanical efficiency of wheelchair exercise. To achieve satisfactory measurements, the wheelchair ergometer requires a stationary location of the wheelchair during propulsion, which can be achieved by placing the wheelchair on rollers (Brouha \& Krobath, I967; Brauer, I972), on a treadmill (Voigt \& Bahn, I969; Hildebrandt et al., 1970) or by mechanically linking the driving wheels to a high inertia flywheel (Brattgard et al., 1970). As these studies with wheelchair ergometry have been with submaximum work levels only, it has not been established whether maximum cardio-respiratory performance during wheelchair propulsion is similar to that achieved by arm cranking. This study was designed to compare the exercise response during both arm cranking and wheelchair ergometry using a multistage progressive work load test in subjects with spinal cord lesions.

\section{Material and Methods}

Seven subjects (four men and three women) were studied of which five had spinal cord lesions. Two subjects were normal males. Their physical characteristics are presented in Table I. Two subjects, both females, were functional tetraplegics, one from a C8 lesion due to a motor vehicle accident and the other having severe disability from childhood poliomyelitis. The two paraplegic males were both internationally competitive wheelchair athletes but at the time of testing were not in training. 
PAPERS READ AT THE ANNUAL SCIENTIFIC MEETING, I 976

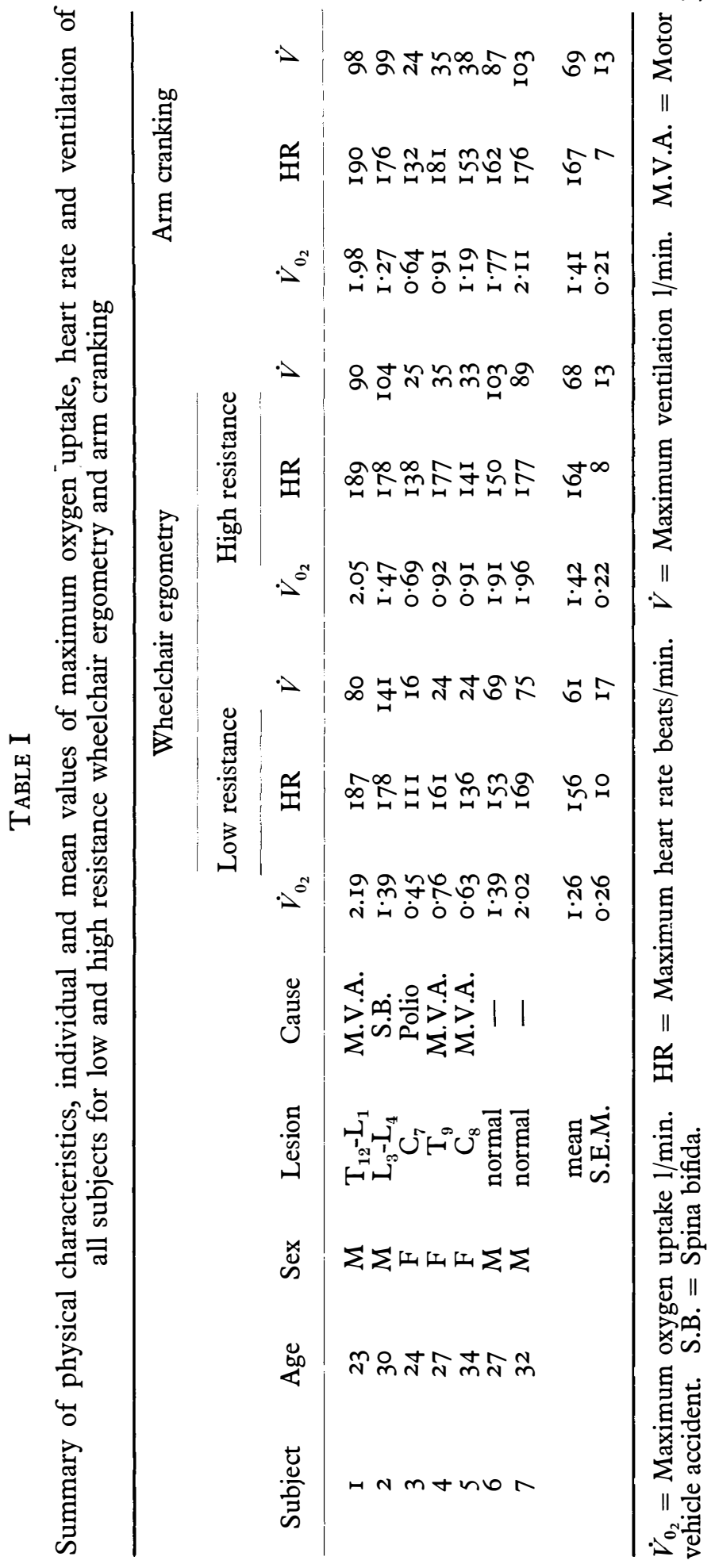


An ergometer based on the design of Brattgard was constructed so as to allow both arm cranking and wheelchair propulsion to be performed independently (Fig. I). The design allowed separate connection of either the wheelchair coupling unit or the hand crank device to a high inertia flywheel (Monark). The pendulum weight which tensions the braking strap around the flywheel was lightened so as to improve the precision of work load setting at low levels of resistance.

The test design for both types of ergometry was that of a multistage progressive work-load test to a symptom-limited maximum performance. With arm cranking, the initial work level was loadless cranking at $60 \mathrm{rpm}$, with increments of either 25 or $50 \mathrm{kpm} / \mathrm{min}$ each minute for tetraplegics and $100 \mathrm{kpm} / \mathrm{min}$ each minute for paraplegic subjects. The work increment was chosen according to the subject's level of spinal cord disability and the estimated fitness.

With wheelchair ergometry, two constant flywheel resistances were used. The first, a low resistance setting ( $0.17 \mathrm{~kg}$ pendulum deflection) simulated the resistance encountered when wheeling on a hard level surface. In establishing this load setting there was a remarkable consistency among subjects in their selection of a resistance that they best felt represented a hard level surface, such as a cement or tiled floor. The second resistance, arbitrarily called a high resistance, was chosen to simulate a more resistive surface, e.g., carpet, a pebbled road, or the ascent of a slight incline. With a constant flywheel resistance, an increment in work load was achieved by progressively increasing the wheelchair speed. From a mechanical calibration of the wheelchair ergometer it was shown that the relationship between increasing wheelchair speed and the resultant power output was linear. Consequently, a progressive work-load test was constructed in which the initial load was 20 wheelchair $\mathrm{rpm}$, i.e. $2 \cdot 3 \mathrm{~km} / \mathrm{h}$, and with each subsequent minute wheelchair speed was increased by Io rpm until the subject was unable to maintain the desired wheelchair speed. For Subject 3, increments of $5 \mathrm{rpm}$ were used because of extensive upper limb involvement.

During exercise the subjects breathed through a low resistance valve. Inspired ventilation was measured with a Parkinson Cowan gas meter and expired gas was continually sampled using an infrared $\mathrm{CO}_{2}$ analyser (Capnograph, Godart) and a paramagnetic $\mathrm{O}_{2}$ analyser (Servomex OA I 50). In recording heart rate a modified placement was necessary to lessen artifact from muscle action. Leads were positioned over the manubrium, sternum and in the midline posteriorly at the level of $\mathrm{TI}_{\mathrm{I}}$. Wheelchair strike frequency, i.e. the frequency with which the subject pushed the wheels was determined by the cyclical variation in power output of a small d.c. generator attached to the end of the main drive shaft of the ergometer. This count was averaged over a 30-40 sec period and expressed as strikes/min.

The three tests, low and high resistance wheelchair ergometry and arm cranking, were performed in random fashion with a minimum rest period of i 5 to 20 min between tests. All tests were performed in the post-prandial state and none of the subjects was taking medication likely to influence the test results.

\section{Results}

\section{Maximum Exercise Capacity}

The differences in maximum values of oxygen uptake, heart rate and ventilation among the three types of activity were small (Table I). The only statistically significant difference was between maximum heart rate of low resistance wheelchair ergometry and arm cranking, I 56.4 $\pm 9 \cdot 8$, I $67^{\circ}$ I $\pm 7 \cdot 4$ (mean \pm I S.E.M.) beats 


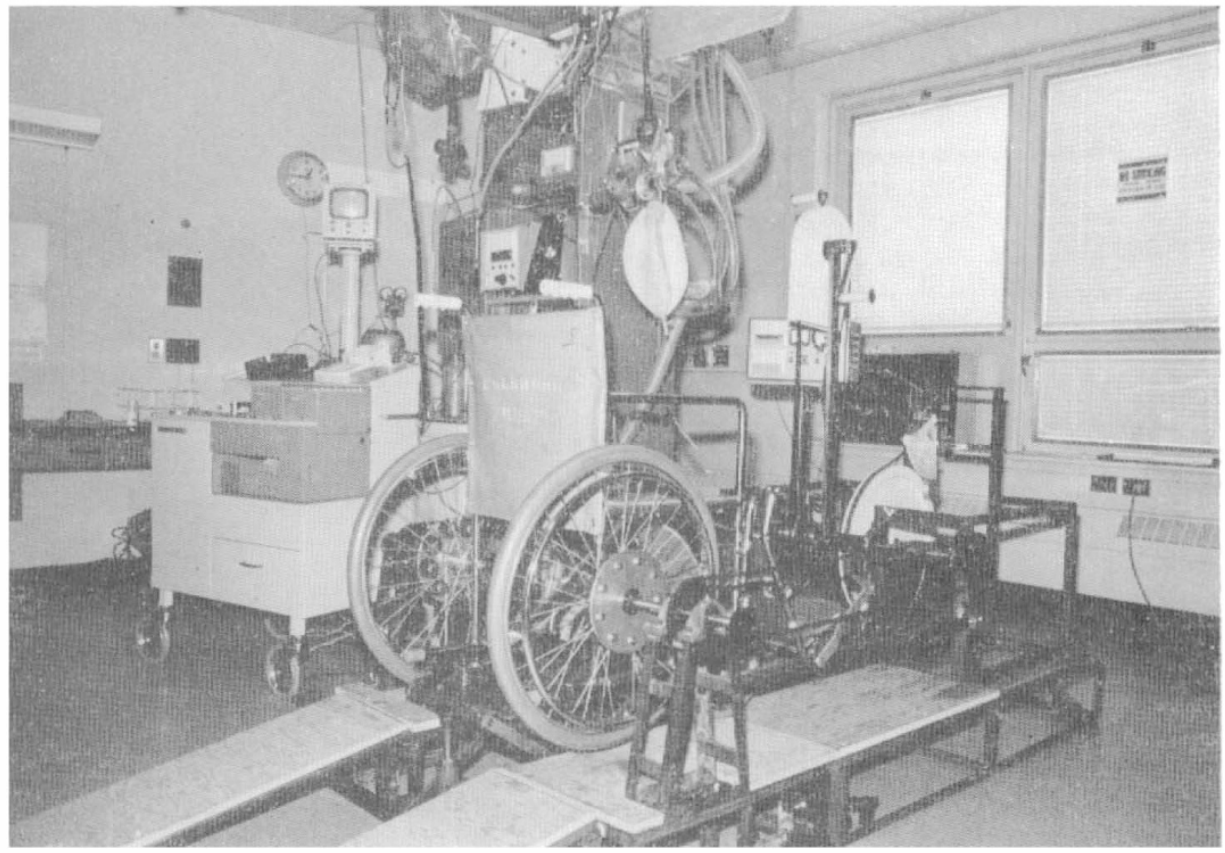

FIG. I

Wheelchair ergometer.

per minute respectively $(\mathrm{P}<0.02)$. Though the maximum oxygen uptakes of low and high resistance wheelchair ergometry and arm cranking, I. $26 \pm 0 \cdot 26, I \cdot 42 \pm$ $0 \cdot 22, \mathrm{I} \cdot 4 \mathrm{I} \pm 0 \cdot 2 \mathrm{I} \mathrm{l} / \mathrm{min}$ were not significantly different, high resistance wheelchair exercise usually exceeded the low resistance performance in the untrained subjects.

\section{Relationship of Oxygen Uptake to Power Output during Arm Cranking}

This relationship was linear (Fig. 2) with only relatively small differences being present among subjects, suggesting that the mechanical efficiency of arm cranking was comparable for all subjects and not influenced by the degree of training of the upper limb musculature. The one exception to this, Subject 3, showed a larger oxygen uptake increment in relationship to increasing work load. This change in mechanical efficiency probably resulted from extensive involvement of the upper limb and shoulder girdle muscles leading to increased work of trunk stabilising muscles.

\section{Relationship of Oxygen Uptake to Wheelchair Ergometry}

Considerable variation in the relationship of oxygen uptake to work load (expressed as wheelchair speed at constant flywheel resistance) was observed among subjects during wheelchair propulsion (Figs. 3 and 4). A greater oxygen uptake at submaximum work loads was seen in the two normal subjects who were unfamiliar with wheelchair use, thus indicating a lower mechanical efficiency. If the energy expenditure at a submaximum work load, e.g. $30 \mathrm{rpm}$ at the high resistance setting, of the two normal subjects is compared with that of the two trained paraplegic males, the respective mean oxygen uptakes are $0.981 / \mathrm{min}$ at $0.461 / \mathrm{min}$ 

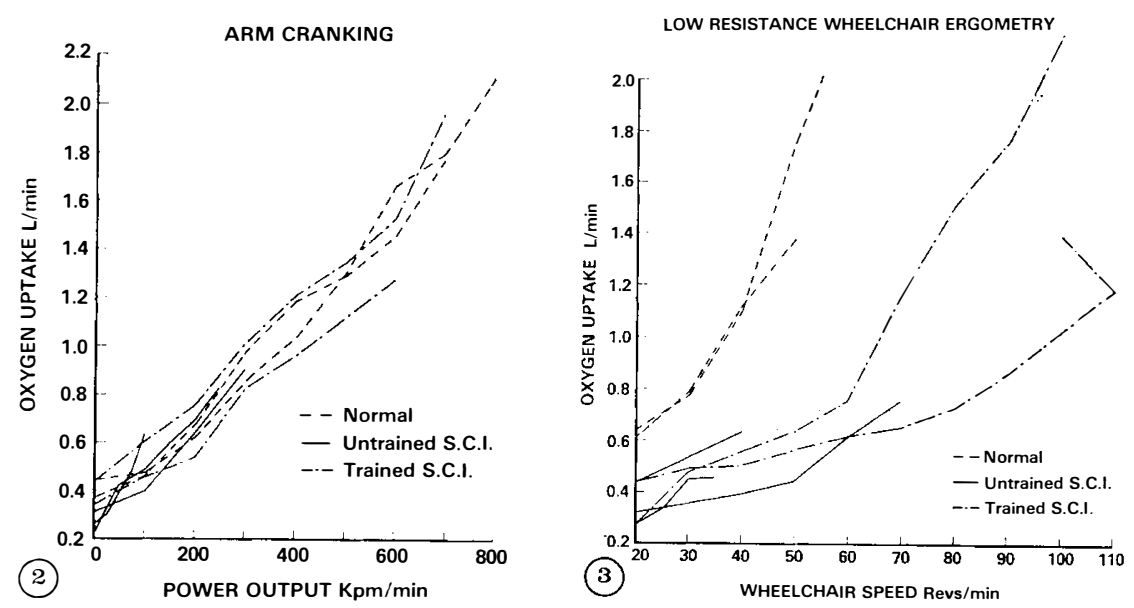

FIG. 2

Relationship of oxygen uptake to work load $(\mathrm{kpm} / \mathrm{min})$ during arm cranking.

FIG. 3

Relationship of oxygen uptake to work load (expressed as wheelchair speed) for low resistance wheelchair ergometry.

indicating at least a two-fold difference in mechanical efficiency. Even at maximum work levels, this difference in efficiency is still present for the disabled males achieved power outputs twice that of the normal subjects at similar maximum oxygen uptakes. The mechanical efficiency of the untrained spinal cord injury subjects was similar to that of the trained males, though the maximum work loads achieved were considerably less.

\section{Relationship of Wheelchair Strike Frequency to Power Output and Oxygen Uptake}

In Figures 5 and 6 the increase in strike frequency which will achieve the desired wheelchair speed for both levels of flywheel resistance is presented. Large differences in the striking rate exist among subjects at submaximum work levels with the lowest strike frequencies being used by the trained males. In these subjects the rate of increase of striking frequency with increasing work load was the least of all subjects. The lowest maximum strike frequencies were seen in Subjects 3 and 4, (the two females) who had involvement of the upper limb musculature. The relationship between striking frequency and oxygen uptake is shown in Figures 7 and 8. For individual subjects, whether male or female, a linear relationship was consistently observed. With regression analysis of combined low and high resistance wheelchair ergometry, a higher correlation was seen in male subjects $(r=0.900$ males, $r=0.64 \mathrm{I}$ females $)$. The greater variation observed in the female subjects may relate to two of these three subjects having a functional motor loss in their upper limbs.

\section{Discussion}

By structuring a multistage progressive work test for wheelchair exercise it has been possible to assess both maximum cardio-respiratory performance and to 

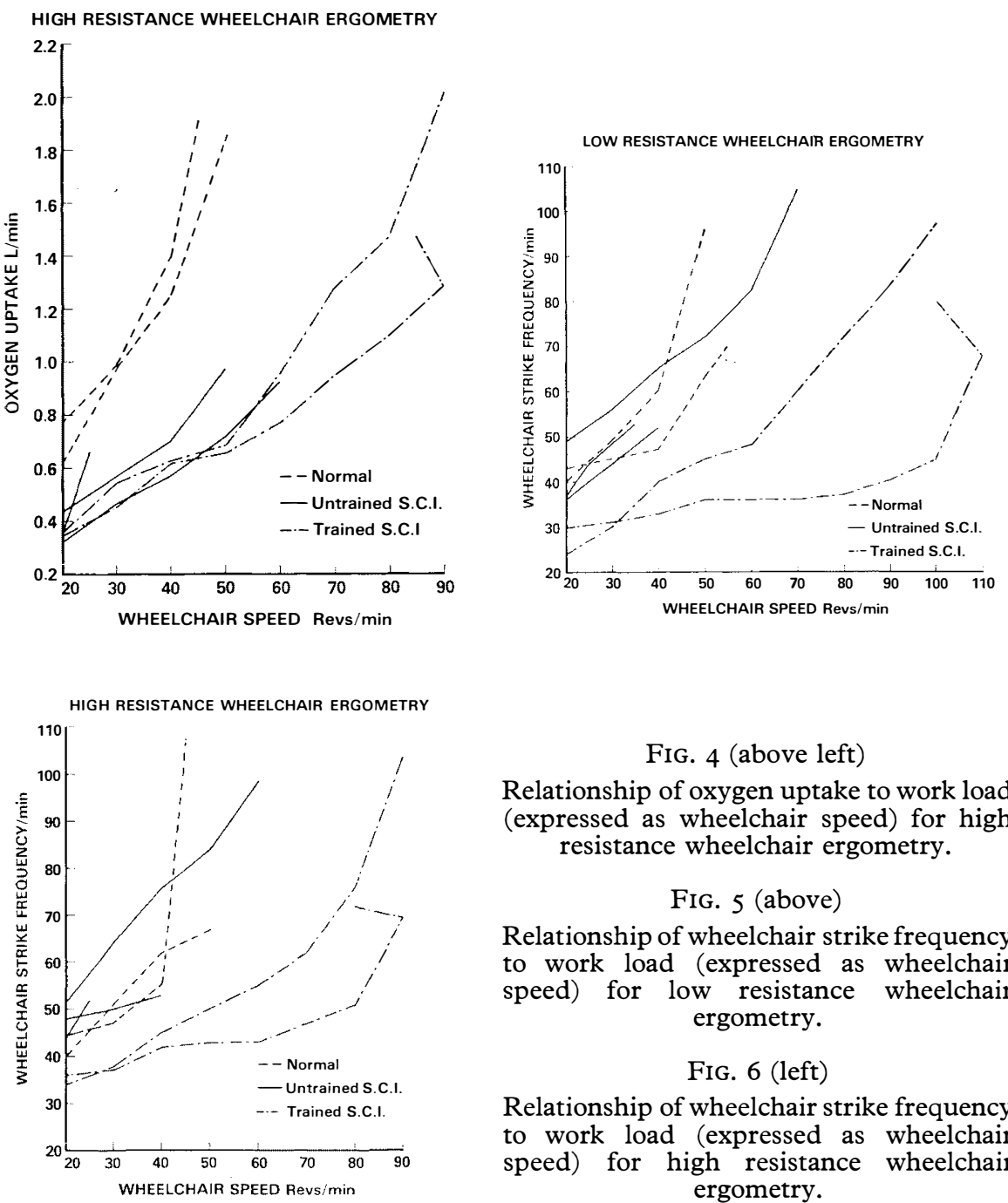

FIG. 4 (above left)

Relationship of oxygen uptake to work load (expressed as wheelchair speed) for high resistance wheelchair ergometry.

FIG. 5 (above)

Relationship of wheelchair strike frequency to work load (expressed as wheelchair speed) for low resistance wheelchair ergometry.

Fig. 6 (left)

Relationship of wheelchair strike frequency to work load (expressed as wheelchair speed) for high resistance wheelchair ergometry.

quantify adaptive mechanisms occurring during wheelchair propulsion. In this study, the differences in maximum oxygen uptake, heart rate and ventilation found between arm cranking and wheelchair ergometry were small, and for high resistance wheelchair exercise these differences were not statistically significant. Corroboration of these similar maximum performances with different types of upper limb exercise (arm cranking and wheelchair propulsion) is not possible as previous studies have considered only submaximum levels of wheelchair exercise (Voigt \& Bahn, 1969; Hildebrandt et al., 1970; Brattgard et al., 1970; Brauer, 1972). An explanation for this relates to the safety of the subject during exercise, for if high levels of performance are necessary, protection from injury is essential. The wheelchair treadmill (Voigt \& Bahn, 1969; Hildebrandt et al., 1970) in contrast to the fixed wheelchair system used in this study has a definite limitation to the maximum speed that it can be safely used; at speeds greater than $4 \mathrm{~km} / \mathrm{h}$, i.e. 35 wheelchair rpm, an accidental fall from the moving belt could result in serious 

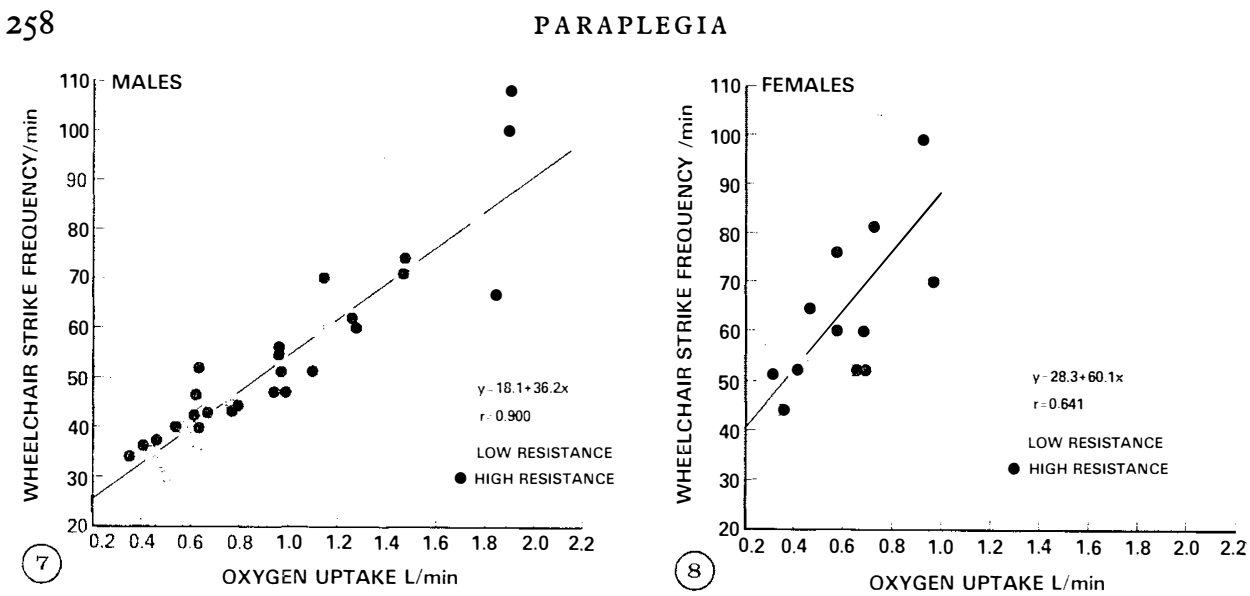

FIG. 7

Relationship of wheelchair strike frequency to oxygen uptake for both low and high resistance wheelchair ergometry (males).

FIG. 8

Relationship of wheelchair strike frequency to oxygen uptake for both low and high resistance wheelchair ergometry (females).

injury. In addition to this the stationary location of the wheelchair facilitates cardio-respiratory measurements.

Despite the unfamiliarity of the two normal subjects with wheelchair propulsion, they achieved a similar maximum oxygen uptake and heart rate as in arm cranking. Among the subjects studied, a major determinant at maximum performance was the functional loss resulting from the spinal cord lesion, this being further modified by training, the specificity of which can be seen with wheelchair testing where differences in performance among subjects were the largest. Because of the smaller numbers in this study, the effect of sex and body weight could not be established.

The observed linear relation between oxygen uptake and power output during arm cranking agrees with the findings of Bobbert (1960), Stenberg et al. (1967), Cotes et al. (1969), and Nilsson et al. (1975). Vokac et al. (1975) during steady state exercise established a curvilinear relationship between oxygen uptake and power output indicating a progressive reduction in mechanical efficiency at higher work levels, this being attributed to the action of postural and stabilising muscles (Stenberg et al., 1967). The effect of impaired trunk stability on oxygen uptake in the small numbers of subjects with spinal cord injury in this study remains uncertain. As a similar oxygen uptake/power output relationship during arm cranking was observed between normal and disabled subjects, it suggested that impaired trunk stability did not significantly affect the efficiency of arm cranking providing that upper limb function was relatively normal. The relationship of oxygen uptake to power output in this study is similar to that observed both in paraplegic males prior to a training programme (Nilsson et al., 1975) and in normal subjects (Stenberg et al., 1967; Vokac et al., 1975).

In contrast to arm cranking, the variation in oxygen uptake/power output relationship during wheelchair ergometry is far larger. among subjects, and for individual subjects, particularly those with the highest mechanical efficiency, it tends to be curvilinear. This is different to the observation by Voigt and Bahn 
(I969) who showed a close correlation between oxygen consumption and the work performed among subjects. Age, sex and the level of disability were said to have little effect on this relationship and the response seen in normal subjects was similar to those with disability. A possible explanation of the difference between these studies is that when using a multistage test, the higher levels of work tend to unmask differences that are of smaller magnitude at submaximum work levels. The interaction of oxygen uptake, power output and strike frequency in this study clearly shows that there are distinct differences among subjects related to the degree of neurological involvement, training, and the familiarity with wheelchair use, the differences being more marked with increasing work load. However, the independent effects of age, sex and the level of disability remain to be established.

The measurement of wheelchair strike frequency is essential in understanding the energy costs of wheelchair propulsion. At similar submaximum work levels males with spinal cord lesions had lower strike frequencies than either the female or normal male subjects, suggesting that maximum efficiency of wheelchair propulsion is achieved by increasing the applied torque to the wheelchair rims during striking, thereby facilitating a lower strike frequency. In Subject 2, a trained male, a progressive increase in power output at submaximum work loads was achieved with only a small increase in strike frequency for both high and low resistance wheelchair ergometry. Oxygen uptake followed a similar trend in that the increments in oxygen uptake were small when the increase in strike frequency was kept to a minimum, but with the need for very high levels of power output, the higher striking frequencies were associated with larger increments in oxygen uptake. From regression analysis (Figs. 7 and 8) a higher oxygen consumption per strike was seen in the male subjects. At a strike frequency of $60 / \mathrm{min}$ the mean oxygen uptake in males was I.I $61 / \mathrm{min}$ but only $0.55 \mathrm{l} / \mathrm{min}$ in females. This difference in oxygen consumption per strike can be analysed by dividing the complete striking cycle into two components: (I) the energy expenditure during the period of torque application to the wheelchair rims and (2) the energy expenditure to return the arms to the starting or prestrike position. In the trained males, an increased energy expenditure per strike can be explained by the higher torques developed and the greater range of upper limb movement during the striking process as these subjects tend to push through a longer distance. Though this study cannot quantify the energy expenditure of these individual components, there appears to be an optimal combination of strike frequency and applied torque which is determined by the upper limb strength and size, neurological function and the maximum wheelchair striking efficiency achieved in response to training. The possible effect of sex was not determined though the findings by Brauer (I972) are of importance, for males with spinal cord injury were able to generate torques $\mathrm{I} \cdot 6$ times that of females when pushing on the rims of a wheelchair which was rigidly locked in place. This difference in upper limb strength during simulated wheelchair striking may explain the disparity between the oxygen cost and strike frequency among subjects.

\section{SUMMARY}

The primary aim of this investigation was to compare maximum wheelchair performance with arm cranking using a multistage progressive work load protocol. In five subjects with a wide range of neurological disability, and two normal males, the differences observed in maximum oxygen uptake, heart rate and ventilation during the two forms of upper limb exercise were not significant. In contrast to 
the small differences in the mechanical efficiency among subjects during arm cranking, much larger differences were observed during wheelchair propulsion. The factors affecting the mechanical efficiency of wheelchair propulsion: upper limb strength, neurological function, and specificity of training of the upper limbs were identified but, due to the small number of subjects, could not be quantified.

\section{RÉSUMÉ}

Cette étude avait pour but principal de comparer les performances maximum d'une chaise roulante avec lancement au moyen du bras, par un rapport travail-charge progressif en plusieurs étapes. Chez cinq sujets présentant divers handicaps neurologiques et deux hommes normaux, les différences observées dans l'absorption maximum d'oxygène, le rythme cardiaque et la ventilation pendant les deux formes d'exercice des membres supérieurs n'étaient pas importantes. Par opposition aux faibles différences d'efficacité mécanique constatées chez les sujets pendant le lancement au bras, des différences beaucoup plus importantes ont été observées pendant la propulsion de la chaise. Les facteurs affectant l'efficacité mécanique de la propulsion de la chaise: force des membres supérieurs, fonction neurologique, et spécificité d'exercice des membres supérieurs, ont été identifiés mais, en raison du petit nombre de sujets, n’ont pu être quantifiés.

\section{ZUSAMMENFASSUNG}

Das primäre Ziel dieser Untersuchung war ein Vergleich maximaler Rollstuhlleistung mit Armkurbel und progressiver Arbeitslast. Bei 5 Untersuchten mit verschiedener neurologischer Disabilität und 2 normalen Kontrollen waren die Unterschiede im maximalen Sauerstoffverbrauch, Herzfrequenz und Ventilation während zweier Formen von Armkurbel Übungen unbedeutend. Dagegen wurden erheblich grössere Unterschiede während Rollstuhlpropulsion gefunden.

\section{REFERENCES}

Bobbert, A. C. (1960). Physiological comparison of three types of ergometry. F. Appl. Physiol. 15, 1007-IOI4.

BRATtGaRd, S. O., GRIMBY, G. \& Hook, O. (1970). Energy expenditure and heart rate in driving a wheelchair ergometer. Scand. $\mathcal{F}$. Rehab. Med. 2, I43-I 48.

BRAUER, R. L. (1972). An ergonomic analysis of wheelchair wheeling. Ph.D. thesis, University of Illinois, Urbana-Champain, Illinois.

BRouHA, L. \& KROBATH, H. (1967). Continuous recording of cardiac and respiratory functions in normal and handicapped persons. Human Factors, 9, 567-572.

Cotes, J. E., Allsopp, D. \& SARDI, F. (1969). Human cardiopulmonary responses to exercise: comparisons between progressive and steady state exercise, between arm and leg exercise, and between subjects differing in body weight. Q.F. Exp. Physiol. 54, 2 II-222.

Hildebrandt, G., Voigt, E. D., Bahn, D., Berendes, B. \& Kroger, J. (I970). Energy costs of propelling wheelchair at various speeds: Cardiac response and effect of steering accuracy. Arch. Phys. Med. Rehab. 5I, I3I-136.

Nilsson, S., Staff, P. H. \& Pruett, E. D. R. (I975). Physical work capacity and the effect of training on subjects with long standing paraplegia. Scand. F. Rehab. Med. 7, $5 \mathrm{I}-56$.

Stenberg, J., Astrand, P. O., Ekblom, B., Royce, J. \& Saltin, B. (1967). Hemodynamic response to work with different muscle groups, sitting and supine. f. Appl. Physiol. 22, 6I-70.

VoIGT, E. D. \& BAHN, D. (I969). Metabolism and pulse rate in physically handicapped when propelling a wheelchair up an incline. Scand. F. Rehab. Med. I, IOI-IO6.

Vokac, Z., Bell, H., BAUTZ-Holter, E. \& Rodahl, K. (I975). Oxygen uptake heart rate relationship in leg and arm exercise, sitting and standing. f. Appl. Physiol. 39, 54-59. 